\section{Flow of Viscoelastic Fluid through a Helical Coil}

\author{
A. Sobti, R. Sehgal, and R. Kumar Wanchoo* \\ Dr. SSB University Institute of \\ Chemical Engineering and Technology, \\ Panjab University, Chandigarh, India-160014
}

\author{
@) (1) \\ This work is licensed under a \\ Creative Commons Attribution 4.0 \\ International License \\ doi: 10.15255/CABEQ.2015.2314 \\ Original scientific paper \\ Received: October 21, 2015 \\ Accepted: March 13, 2017
}

\begin{abstract}
The study aims at quantifying the effect of fluid elasticity on frictional pressure drop for the flow of viscoelastic fluid through a helical coil. Aqueous solutions of polyacrylamide (PAA) in the concentration range $0.25 \%-0.5 \%$ (wt/vol.) were used as test fluids. The fluids were characterized using dynamic rheometer under rotational and oscillatory modes. The rheological study depicts that the fluids exhibit elasticity and shear thinning behavior. Experimental data on pressure drop for the flow of non-Newtonian viscoelastic fluid through a helical coil have been generated. Drag enhancement was observed for the fluids with significant elastic character. An existing correlation applicable over a wide range of Germano number $\left(N_{G n}\right)$ for the flow of Newtonian fluids through helical coils $(11.7 \leq D / d \leq 105.48,8.3 \leq p / D \leq 66.7)$, proposed by Gupta et al. ${ }^{22}$, has been extended to non-Newtonian viscoelastic fluids by incorporating the effect of fluid elasticity in terms of Weissenberg number $(\mathrm{We})$. The proposed model's uncertainty has been reported for $95 \%$ confidence to assess the significance of newly reported results. The observed data were compared with the available models in the literature statistically using mean relative quadratic error $(M R Q E)$ and arithmetic relative error $(\% A R E)$. Lower values of $M R Q E$ and $\% A R E$ depict the acceptability of the proposed model.
\end{abstract}

Key words

pressure drop, viscoelastic fluid, helical coil, fluid elasticity, Germano number, Weissenberg number

\section{Introduction}

Helical coils are widely used in heat exchangers, chemical reactors and other devices due to enhanced heat and mass transfer coefficients and large transfer area per unit volume ${ }^{1-5}$. The enhancement of heat and mass transfer in coils occur due to the existence of a secondary flow ${ }^{6,7}$. When a fluid flows through a curved tube, centrifugal force acts outward from the centre of the curvature on the fluid element. There must be a pressure gradient across the tube required to balance the centrifugal force arising from the curvature. The fluid near the tube walls moves very slowly compared to the central plane due to its viscosity and hence requires a smaller pressure gradient to balance its centrifugal force. This leads to the onset of secondary flow in which the fluid near the central plane moves outward and the fluid near the walls moves towards the central plane ${ }^{8,9}$. This in turn modifies the axial velocity and increases the flow resistance ${ }^{10}$. This increase in frictional pressure drop was observed by various investigators in the case of flow through helical coils, compared to straight tubes, in similar

\footnotetext{
${ }^{*}$ Corresponding author; Email: wanchoo@pu.ac.in;
}

Phone: +91-1722534933 conditions ${ }^{11}$. The flow phenomenon in curved tubes is therefore more complex, because of the existence of secondary flow.

The investigations by Dean ${ }^{12,13}$ on the motion of fluid in a curved pipe reveal that such type of flow depends on the Dean number, a dimensionless parameter $D e=\operatorname{Re}\left(\frac{d_{t}}{D_{c}}\right)^{0.5}$; however, the analysis was restricted to small values of $D e$. For large values of Dean number, Barua ${ }^{9}$ proposed a theoretical expression (Eq. 1) for determining the resistance coefficient.

$$
\left(\frac{f_{c}}{f_{s}}\right)=0.0918 D e^{0.5}+0.509
$$

Equation 1 agrees well with the experimental observations of White ${ }^{14}$ and Alder ${ }^{15}$ for Dean number up to 10000 , but for laminar flow only (White ${ }^{14}$, Alder ${ }^{15}$ and Eustice ${ }^{16}$ ).

Many review articles are available to understand the flow behavior and transfer processes in Newtonian and non-Newtonian fluids through helical coils. Ito ${ }^{10}$ and Berger et al. ${ }^{17}$ gave clear and thoughtful concepts on flow through curved pipes. 
Naphon and Wongwises ${ }^{11}$ and Zhou and Shah ${ }^{18}$ have presented critical reviews on flow and heat transfer characteristics of Newtonian and non-Newtonian fluids flowing through helical coils. Vashisth et al. ${ }^{19}$ have carried out an extensive literature review on applications of curved geometries for various operations involving mixing, heat- and mass transfer. Mishra and Gupta ${ }^{20}$ have reported pressure drop data for the flow of Newtonian fluids through curved pipes covering the wide range of $0 \leq p / d_{t} \leq$ 25.4 and $0.003 \leq d / D_{c} \leq 0.15$ with 60 helical coils and proposed an empirical correlation, expressed as:

$$
\left(\frac{f_{c}}{f_{s}}\right)=1+0.033\left(\log _{10} N_{D_{m}}\right)^{4}
$$

Mishra and Gupta ${ }^{21}$ further extended Eq. 2 to non-Newtonian fluids where the Dean number is defined on the basis of viscosity prevailing at the mean wall shear stress. The proposed correlation is expressed as:

$$
\left(\frac{f_{c}}{f_{s}}\right)=1+0.033\left(\log _{10} N_{D_{2}}\right)^{4}
$$

where $\quad N_{D_{2}}=\operatorname{Re}_{2}\left(\frac{d_{t}}{D_{c}}\right)^{0.5}$

and

$$
\operatorname{Re}_{2}=\frac{d_{t} \rho V}{\mu_{2}}
$$

The viscosity prevailing at the mean wall shear stress can be defined based on apparent consistency index $\left(K^{\prime}\right)$, and is expressed as:

$$
\mu_{2}=K^{\prime}\left(\frac{8 U}{d_{t}}\right)^{n^{\prime}-1}
$$

with

$$
K^{\prime}=K\left(\frac{3 n+1}{4 n}\right)^{n} ; n=n^{\prime}
$$

Since neither Reynolds number nor Dean number alone can elucidate the combined effect of the curvature ratio $\left(d_{t} / D_{c}\right)$ and pitch ratio $\left(p / d_{t}\right)$, Gupta et $a{ }^{22}$, in their study, chose the Germano number $\left(N_{G n}\right)$, which explains the combined effect of the curvature ratio and pitch ratio, to correlate the friction factor data on Newtonian fluids flowing through helical coils. Extensive pressure drop data were generated covering a wide range of curvature ratio $\left(0.0855 \leq d_{t} / D_{c} \leq 9.48 \cdot 10^{-3}\right)$ and pitch ratio $\left(8.3 \leq p / d_{t} \leq 66.7\right)$ and proposed the following empirical correlation:

$$
\begin{aligned}
& \frac{f_{c}}{f_{s}}=1+0.903 N_{G n}^{0.227} \text { for } N_{G n} \leq 70 \\
& \frac{f_{c}}{f_{s}}=1+0.525 N_{G n}^{0.516} \text { for } N_{G n}>70
\end{aligned}
$$

where

$$
N_{G n}=\operatorname{Re} \cdot \tau_{n}
$$

and

$$
\tau_{n}=\frac{\pi\left(\frac{p}{d_{t}}\right)}{\left(\frac{p}{d_{t}}\right)^{2}+\left(\frac{\pi D_{c}}{d_{t}}\right)^{2}}
$$

The effect of helix angle of coiled tube for single as well as two-phase flow of non-Newtonian viscoinelastic power law fluids was studied by Bandaru and $\mathrm{Chhabra}^{23}$ under laminar as well as turbulent flow conditions. The effect of helix angle on pressure drop was found to be negligible under laminar flow regime. However, the pressure drop increases with increase in helix angle under turbulent flow conditions. The following correlation based on modified Dean number (De') was proposed by Bandaru and Chhabra ${ }^{23}$ :

$$
\begin{gathered}
\left(\frac{f_{c}}{f_{s}}\right)=1+0.0225\left(D e^{\prime}\right)^{0.784} \\
D e^{\prime}=\operatorname{Re}^{\prime}\left(\frac{d_{t}}{D_{c}}\right)^{0.5} \\
\operatorname{Re}^{\prime}=\frac{d_{t}^{n^{\prime}} \rho V^{2-n^{\prime}}}{m^{\prime} 8^{n^{\prime-1}}}
\end{gathered}
$$

Mashelkar and Devaranjan ${ }^{24}$ have incorporated the effect of the flow behavior index in the coefficient and exponent of modified Dean number for the flow of non-Newtonian inelastic fluids through coils for the curvature ratio, $d_{t} / D_{c}<0.1$. The proposed correlation is expressed as:

$$
f_{c}=\left(\begin{array}{l}
\left(9.069-9.438 n+4.374 n^{2}\right) \\
\cdot\left(\frac{d_{t}}{D_{c}}\right)^{0.5} \cdot\left(D e^{\prime}\right)^{-0.768+0.122 n}
\end{array}\right)
$$

Mashelkar and Devaranjan ${ }^{25}$ further extended their own correlation (Eq. 6), to be applicable for the flow of non-Newtonian viscoelastic fluids (PAA and PEO, $100 \leq C_{v e} \leq 5000 \mathrm{ppm}$ ) through coils, by incorporating the effect of fluid elasticity in terms of Weissenberg number $(W e)$. The correlation was developed for very high values of $W e(40<W e<$ 950 ), which had been defined on the basis of boundary layer thickness and not the characteristic dimension of the conduit. The phenomenon of drag reduction was observed with the increase in Weissenberg number. The following expression was proposed to determine the friction factor in the case of flow of viscoelastic fluids through coils: 


$$
\begin{aligned}
f_{c}= & \left(\begin{array}{l}
\left(9.069-9.438 n+4.374 n^{2}\right) \cdot \\
\cdot\left(\frac{d_{t}}{D_{c}}\right)^{0.5} \cdot\left(D e^{\prime}\right)^{-0.768+0.122 n} \cdot
\end{array}\right) . \\
& \cdot\left(1-0.03923 W e^{0.2488}\right)
\end{aligned}
$$

The effect of fluid elasticity on frictional pressure drop has recently been studied by Pimenta and Campos $^{26}$. Based on their experimental data, the existing correlation of Hart et al..$^{27}$ was modified. The authors have shown an enhancement in drag for non-Newtonian viscoelastic fluid (XG) over non-Newtonian inelastic fluid (CMC) for the same range of Dean number. However, the effect of fluid elasticity in terms of Deborah or Weissenberg number has not been incorporated in their proposed correlation, expressed as:

$$
\left(\frac{f_{c}}{f_{s}}\right)=1+\left(\frac{0.028\left(D e^{\prime}\right)^{1.68}}{70+D e^{\prime}}\right)
$$

Table 1 represents the available correlations proposed by various researchers for predicting the frictional pressure drop in case of flow through helical coils, applicable under different geometrical and flow conditions.

The literature cited above clearly shows that very limited knowledge is available for predicting the frictional pressure drop in the case of flow of viscoelastic fluids through helical coils. The available studies contradict each other in terms of drag enhancement or drag reduction. There is insufficient data in the literature on frictional pressure drop in the case of viscoelastic flow through helical coils, which requires further attention. In addition, the available correlations lack universal character, as most of these do not satisfy the boundary condition, i.e., $f_{c} / f_{s} \rightarrow 1$ as $D e$ or $D e^{\prime} \rightarrow 0$, and are applicable to certain geometrical or flow conditions $\mathrm{s}^{19,22}$. The present study aims to fulfill some of the above shortcomings.

\section{Experimental}

\section{Experimental setup and procedure for pressure drop measurement}

The helical coil, made by rolling silicon tubing ( $8.49 \mathrm{~mm}$ inner diameter and $11.46 \mathrm{~mm}$ outer diameter) around a cylindrical base $(200.7 \mathrm{~mm}$ outer diameter), with curvature ratio $\left(d_{t} / D_{c}\right)$ and pitch ratio $\left(p / d_{t}\right), 0.04$ and 1.35, respectively, has been used in the present study. Based on the number of turns of the coil (i.e. 14), the outer diameter of the tube and the cylindrical coil support (200.7 $\mathrm{mm}$ outer diameter), the equivalent length of the coil was established at $9.75 \mathrm{~m}$. The schematic diagram of the experimental setup used for the measurement of pressure drop across the helical coil is given in Fig. 1. The flow through the helical coil was circulated from a cylindrical tank maintained at a constant air pressure of $1.75 \mathrm{~kg}_{\mathrm{f}} \mathrm{cm}^{-2}$ (gauge), using a pressure regulator, to provide a constant flow rate of test fluid for a particular valve opening. The pressure drop across the coil, for different flow rates, was measured using a U-tube manometer filled with mercury, and the volumetric flow rate was measured at the exit using a measuring cylinder. The experimental setup was first calibrated using a straight tube, and water as a test fluid. The data were found to be in close agreement with standard correlations ${ }^{28}$ for laminar and turbulent flow, respectively, expressed as:

$$
f_{s}=\frac{16}{\operatorname{Re}}
$$
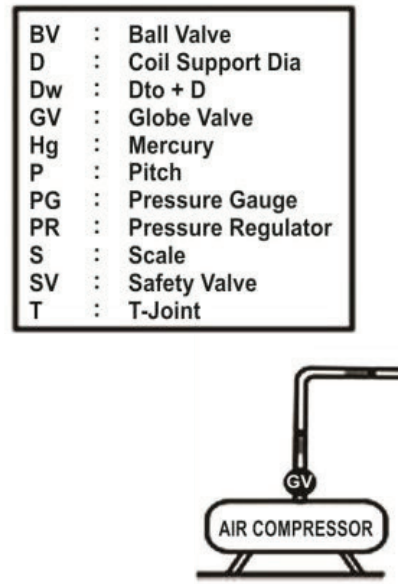

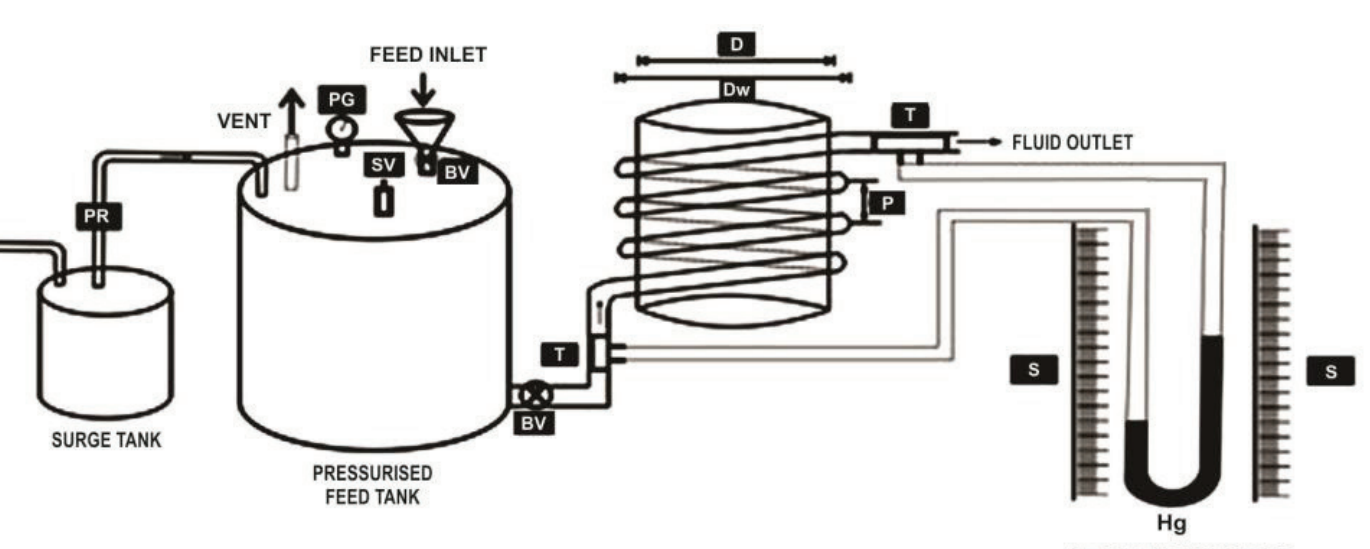

U-TUBE MANOMETER

Fig. 1 - Experimental setup 


$$
f_{s}=0.0014+\frac{0.125}{\operatorname{Re}^{0.32}}
$$

The experimental friction factor for helical coil was calculated using the following expression:

$$
f_{c}=\frac{\Delta P}{L_{c}} \frac{d_{t}}{2 \rho U^{2}}
$$

where,

$$
\Delta P=R_{m}\left(\rho_{H g}-\rho_{f}\right) g
$$

The flow behavior through helical coils was generally governed by Dean number $(D e)$ which is a function of curvature ratio $\left(d / D_{c}\right)$ and can be calculated using Eq. 12 for Newtonian fluids ${ }^{22}$. In the present study, De for the flow of non-Newtonian fluids is determined by replacing dynamic viscosity with apparent viscosity $\left(\mu_{a}=K \dot{\gamma}^{n-1}\right)$.

$$
D e=\operatorname{Re}\left(\frac{d_{t}}{D_{c}}\right)^{0.5}
$$

where,

$$
\operatorname{Re}=\frac{d_{t} \rho U}{\mu}
$$

and

$$
D_{c}=D_{w}\left[1+\left(\frac{p}{\pi D_{w}}\right)^{2}\right]
$$

with

$$
D_{w}=D+D_{t o}
$$

Germano number $\left(N_{G n}\right)$ is based on Eq. 4b. The shear rate encountered at the wall was determined using the following expression ${ }^{21}$ :

$$
\dot{\gamma}=\frac{3 n+1}{4 n} \cdot \frac{8 U}{d_{t}}
$$

For a given curvature ratio, the critical value of Reynolds number was determined using the follow-

\begin{tabular}{|c|c|c|}
\hline Reference & Proposed Correlation & Remarks \\
\hline Barua $^{9}$ & $\left(\frac{f_{c}}{f_{s}}\right)=0.0918 D e^{0.5}+0.509$ & Theoretical model for large Dean numbers. \\
\hline $\begin{array}{l}\text { Mishra and } \\
\text { Gupta }^{20}\end{array}$ & $\left(\frac{f_{c}}{f_{s}}\right)=1+0.033\left(\log _{10} N_{D_{m}}\right)^{4}$ & $\begin{array}{l}\text { - Empirical correlation for Newtonian fluids for } 1< \\
N_{D m}<3000,0 \leq p / d_{t} \leq 25.4 \text { and } 0.003 \leq d_{t} / D_{c} \leq 0.15\end{array}$ \\
\hline $\begin{array}{l}\text { Mishra and } \\
\text { Gupta }^{21}\end{array}$ & $\begin{array}{l}\left(\frac{f_{c}}{f_{s}}\right)=1+0.033\left(\log _{10} N_{D_{2}}\right)^{4} \\
N_{D_{2}}=\operatorname{Re}_{2}\left(\frac{d_{t}}{D_{c}}\right)^{0.5}, \quad \operatorname{Re}_{2}=\frac{d_{t} \rho V}{\mu_{2}} \\
\mu_{2}=K^{\prime}\left(\frac{8 U}{d_{t}}\right)^{n^{\prime}-1}\end{array}$ & $\begin{array}{l}\text { - Empirical correlation for non-Newtonian fluids } \\
\text { where modified Dean number is defined on basis of } \\
\text { viscosity prevailing at the mean wall shear stress. }\end{array}$ \\
\hline $\begin{array}{l}\text { Bandaru and } \\
\text { Chhabra }^{23}\end{array}$ & $\begin{array}{l}\left(\frac{f_{c}}{f_{s}}\right)=1+0.0225\left(D e^{\prime}\right)^{0.784} \\
D e^{\prime}=\operatorname{Re}^{\prime}\left(\frac{d_{t}}{D_{c}}\right)^{0.5}, \quad \operatorname{Re}^{\prime}=\frac{d_{t}^{n^{\prime}} \rho V^{2-n^{\prime}}}{m^{\prime} 8^{n^{\prime-1}}}\end{array}$ & $\begin{array}{l}\text { - Experimental correlation for single as well as } \\
\text { two-phase flow of non-Newtonian viscoinelastic } \\
\text { fluids. Effect of helix angle was determined under } \\
\text { laminar and turbulent flow conditions for } \\
0.2 \leq D e^{\prime} \leq 1000,0.57 \leq n^{\prime} \leq 1\end{array}$ \\
\hline $\begin{array}{l}\text { Mashelkar and } \\
\text { Devaranjan }^{24}\end{array}$ & $f_{c}=\left(\left(9.069-9.438 n+4.374 n^{2}\right)\left(\frac{d_{t}}{D_{c}}\right)^{0.5}\left(D e^{\prime}\right)^{-0.768+0.122 n}\right)$ & $\begin{array}{l}\text { - Theoretical correlation for purely viscous non- } \\
\text { Newtonian fluids for } D e^{\prime}>100, d_{t} / D_{c}<0.1 \text { and } \\
0.5 \leq n \leq 1\end{array}$ \\
\hline $\begin{array}{l}\text { Mashelkar and } \\
\text { Devaranjan }^{25}\end{array}$ & $\begin{aligned} f_{c}= & \left(\left(9.069-9.438 n+4.374 n^{2}\right)\left(\frac{d_{t}}{D_{c}}\right)^{0.5}\left(D e^{\prime}\right)^{-0.768+0.122 n}\right) \\
& \cdot\left(1-0.03923 W e^{0.2488}\right)\end{aligned}$ & $\begin{array}{l}\text { - Empirical and theoretical correlation for power law } \\
\text { viscoelastic solutions (PAA and PEO), } 70 \leq D e \leq \\
400,0.01 \leq d_{t} / D_{c} \leq 0.135 \text { and } 0.35 \leq n \leq 1,40< \\
W e<950,100 \leq C_{v e} \leq 5000 \mathrm{ppm} \\
\text { - Weissenberg number is defined on the basis of } \\
\text { boundary layer thickness. }\end{array}$ \\
\hline $\begin{array}{l}\text { Pimenta and } \\
\text { Campos }^{26}\end{array}$ & $\left(\frac{f_{c}}{f_{s}}\right)=1+\left(\frac{0.028\left(D e^{\prime}\right)^{1.68}}{70+\left(D e^{\prime}\right)}\right)$ & $\begin{array}{l}\text { - Correlation of Hart et al. }{ }^{27} \text { was modified based on } \\
\text { their observed experimental data for Newtonian, } \\
\text { viscoinelastic (CMC) and viscoelastic fluids (XG). }\end{array}$ \\
\hline Hart et al. ${ }^{27}$ & $\left(\frac{f_{c}}{f_{s}}\right)=1+\left(\frac{0.090 D e^{1.5}}{70+D e}\right)$ & Theoretical correlation for Newtonian fluids \\
\hline
\end{tabular}
ing correlation of Srinivasan et al. ${ }^{29}$ :

$$
\operatorname{Re}_{c r i t}=2100\left[1+12\left(\frac{d_{t}}{D_{c}}\right)^{0.28}\right]
$$

\section{Uncertainty analysis}

Describing the uncertainty in the experimental results offers the experimenter a rational way of

Table 1 -Friction factor correlations commonly used in curved tubes under different flow conditions 
evaluating the significance of the scatter on repeated trials ${ }^{30}$ and helps in ascertaining the propagation of errors from individual quantities to the derived variables. The uncertainty in the experimental results was determined using the methods of Moffat ${ }^{30}$, and Kline and McClintock ${ }^{31}$. The maximum uncertainty in estimating the coil friction factor $(f)$, Reynolds number $(\mathrm{Re})$ and Germano number $\left(N_{G n}^{c}\right)$ was within $\pm 6.53 \%, 0.79 \%$ and $\pm 1.27 \%$, respectively. However, the uncertainties in the majority of the reported experimental data are much lower than the maximum value.

\section{Results and discussion}

\section{Characterization of test fluids}

The test fluids used in the present study include aqueous solutions of polyacrylamide (PAA $-0.25 \%$, $0.3 \%, 0.4 \%$ and $0.5 \%$ (wt/vol.)) having viscosity average molecular wt. of $8 \cdot 10^{6}$, procured from National Chemicals, Vadodara, India. The method of preparing the test fluids has been described in detail elsewhere ${ }^{32}$. The density of each test fluid was measured using specific gravity bottle, which was initially calibrated using mercury as a standard fluid. The oscillatory and steady shear rate experiments were made on polyacrylamide solutions using a modular compact rheometer (MCR-102) of Anton Paar $\mathrm{GmbH}$, Graz, Austria. A cone and plate geometry having cone angle $1^{0}$ and diameter $50 \mathrm{~mm}$ was used with MCR102 for rheological measurements. The results show that the test solutions exhibit shear thinning behavior which can adequately be approximated by two parameter power law model that can be expressed as:

$$
\tau=K \dot{\gamma}^{n}
$$

The observed data were fitted to Eq. 15 over the range of shear rate encountered in the helical coil, and the model parameters evaluated using nonlinear regression technique. Further, the observed oscillatory data $\left(G, G^{\prime \prime}\right.$ versus $\left.\omega\right)$ were fitted to well-known four elements Maxwell model, expressed as:

$$
G^{\prime}=\sum_{i=1}^{4} \frac{\eta_{i} \lambda_{i} \omega^{2}}{1+\left(\lambda_{i} \omega\right)^{2}}
$$

$$
G^{\prime \prime}=\sum_{i=1}^{4} \frac{\eta_{i} \omega}{1+\left(\lambda_{i} \omega\right)^{2}}
$$

The values of fluid relaxation time $(\lambda)$, characterizing the fluid elasticity, was estimated using the following expression: ${ }^{33}$

$$
\lambda_{t}=\frac{\sum_{i=1}^{4} \lambda_{i} \eta_{i}}{\sum_{i=1}^{4} \eta_{i}}
$$

The observed physical and rheological properties of the test fluids under study are given in Table 2.

\section{Pressure drop studies for viscoelastic fluids}

The observed pressure drop flow rate data for the flow of non-Newtonian viscoelastic fluids through helical coil, in the concentration range of $0.25-0.5 \%$ (wt/vol.), as a function of Reynolds number are represented in Fig. 2. The pressure drop per unit length $\left(\Delta P / L_{c}\right)$ of coil increases with increase in Reynolds number (Re). However, an appreciable rise in pressure drop was observed for higher concentrations $(0.4 \%$ and $0.5 \%(\mathrm{wt} / \mathrm{vol})$. compared to $0.25 \%$ and $0.3 \%$ for the same Reynolds number. Fig. 3 represents the coil friction factor $(f)$ data as a function of Germano number $\left(N_{G n}\right)$.

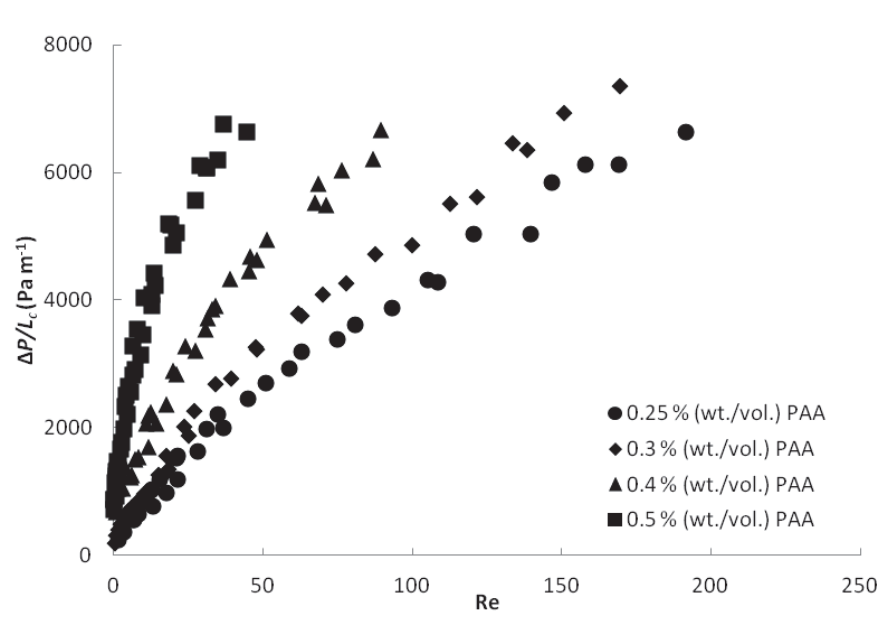

Fig. 2 - Observed pressure drop per unit length of coil ( $\triangle P /$ $L$ ) versus Reynolds number (Re) for non-Newtonian viscoelastic fluids flowing through helical coil

Table 2 - Physical and rheological properties of test fluids

\begin{tabular}{l|c|c|c|c|c}
\hline \multicolumn{1}{c}{ Test fluid } & Temperature $\left({ }^{\circ} \mathrm{C}\right)$ & $K\left(\mathrm{~Pa} \mathrm{~s}^{\mathrm{n}}\right)$ & $n$ & $\lambda_{t}(\mathrm{~s})$ & $\rho_{f}\left(\mathrm{~kg} \mathrm{~m}^{-3}\right)$ \\
\hline PAA $(0.25 \% \mathrm{wt} / \mathrm{vol})$. & $17 \pm 0.01$ & 0.152 & 0.575 & 0.826 & 998.85 \\
PAA $(0.3 \% \mathrm{wt} / \mathrm{vol})$. & $17 \pm 0.01$ & 0.202 & 0.539 & 1.206 & 999 \\
PAA $(0.4 \% \mathrm{wt} / \mathrm{vol})$. & $17 \pm 0.01$ & 0.359 & 0.476 & 2.431 & 999.7 \\
PAA $(0.5 \% \mathrm{wt} / \mathrm{vol})$. & $17 \pm 0.01$ & 0.639 & 0.419 & 4.707 & 1000.82 \\
\hline
\end{tabular}




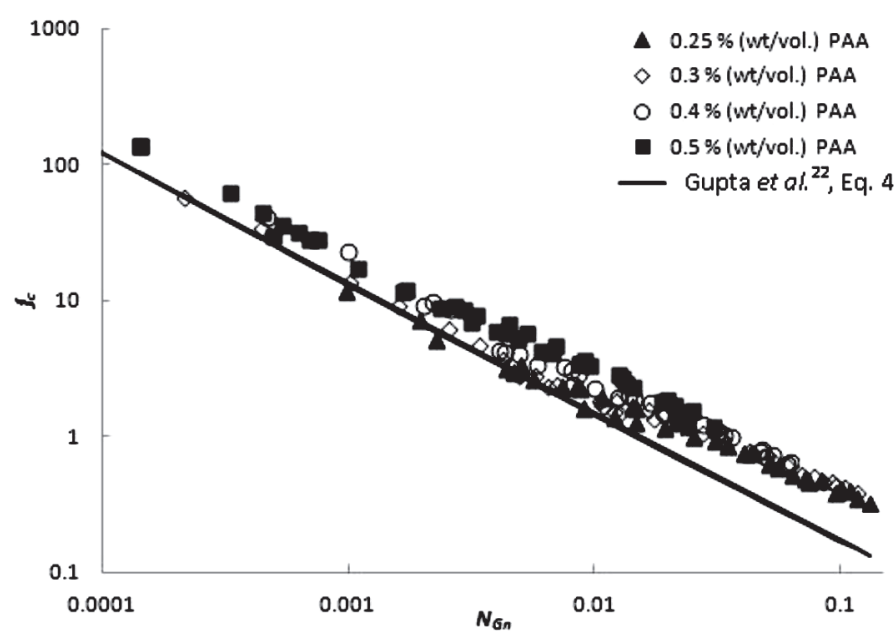

Fig. 3 - Observed friction factor in coil, $f_{c}$ versus $N_{G n}$ for Newtonian and non-Newtonian viscoelastic fluids flowing through helical coil

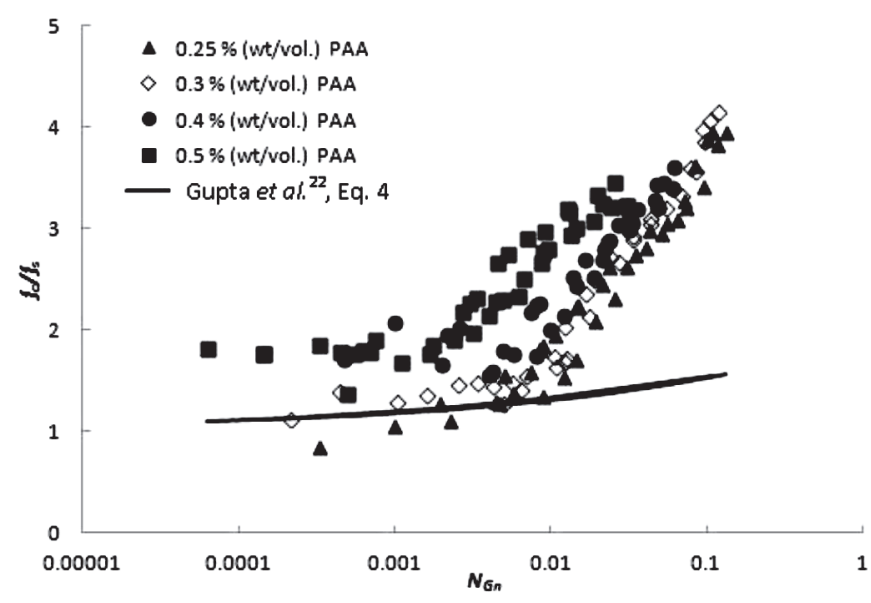

Fig. 4 - Friction factor ratio $\left(f_{c} / f\right)$ versus $N_{G n}$ for Newtonian and non-Newtonian viscoelastic fluids flowing through helical coil

For the purpose of comparison with Newtonian fluids, the model proposed by Gupta et al. ${ }^{22}$ was selected because it is based on $N_{G n}$ which takes into account the combined effect of various geometrical parameters, such as curvature ratio and pitch ratio. Moreover, the correlation was developed through an extensive parametric study $\left(11.7 \leq D_{c} / D_{t} \leq 105.48\right.$ and $\left.8.3 \leq p / D_{t} \leq 66.7\right)$ and is applicable over a wide range of $N_{G n}$. The model predicted data (Eq. 4) for Newtonian fluids are also represented in Fig. 3 along with the present experimental data. The phenomenon of drag enhancement was observed for the flow of viscoelastic fluids through helical coil compared to that of Newtonian fluids. The ratio of the experimental friction factor in the coil to that in the straight tube $\left(f_{c} / f_{s}\right)$ for viscoelastic fluids (PAA $0.25-0.5 \%$ (wt/vol. )) along with the model predicted data (Eq. 4) for Newtonian fluid (water) against $N_{G n}$, is represented in Fig. 4, which depicts the dom- inance of elastic effects over viscous effects at critical value of $N_{G n}$. There seems to be a critical value of Germano number $\left(N_{G n} \sim 0.002\right)$ beyond which a sharp increase in friction factor has been observed for the concentrations under study. The increased frictional resistance may be attributed to extensional stresses, which develop as a result of chain elongation. This shows the dominance of elastic effects over viscous effects, resulting in the stretching flow. These elastic effects need to be incorporated in the existing model for Newtonian fluids, in terms of Weissenberg number $(\mathrm{We})$. The Weissenberg number, defined as the product of characteristic time of material and the characteristic rate of deformation, was introduced by White ${ }^{34}$ (cited by Dealy ${ }^{35}$ ), which has also been expressed in the open literature as the ratio of fluid characteristic time to the process characteristic time ${ }^{36,37}$ is given below:

$$
W e=\frac{\lambda_{t} U}{d_{t}}
$$

where $\lambda_{t}$ is the fluid relaxation time representing the fluid elasticity; $U$ is the superficial velocity; $d_{t}$ is the inner tube diameter.

\section{Generation of empirical correlation for viscoelastic fluids}

Based on the discussion in previous section, the following empirical model is proposed for the flow of viscoelastic fluids through helical coils:

$$
\left(\frac{f_{c}}{f_{s}}\right)_{v e}=\left(\frac{f_{c}}{f_{s}}\right)_{n}\left(1+a W e^{b}\right)
$$

In the present study, the observed $N_{G n}$ is $\leq 70$. The friction factor ratio for coils to that of straight tubes for the Newtonian fluids $\left(f_{c} / f_{n}\right.$ is expressed by Eq. 4, proposed by Gupta et al. ${ }^{22}$ The proposed correlation (Eq. 19) follows the boundary conditions $\left(f_{c} / f_{s}\right)_{v e} \rightarrow\left(f_{c} / f_{s}\right)_{n}$ when $W e \rightarrow 0$ and $f_{c} \rightarrow f_{s}$ for $N_{G n} \rightarrow 0$ and, simultaneously takes into account the combined effect of curvature ratio and pitch ratio. Fig. 5 represents the functional relationship between drag enhancement $\left[\left(\left(f_{c} / f_{s}\right)_{v e} /\left(f_{c} / f\right)_{n}\right)-1\right]$ and Weissenberg number. Using nonlinear regression technique, the values of model constants $(\mathrm{a}, \mathrm{b})$ were determined as 0.23 and 0.43 , respectively, with regression coefficient of 0.95 . The proposed model's uncertainty has been reported for $95 \%$ confidence $^{30}$ to assess the significance of newly reported results. Table 3 represents the results obtained using nonlinear regression technique. The proposed model (Eq. 19) has been evaluated for the fluids with significant elastic character $\left(0.826 \leq \lambda_{t} \leq 4.707\right)$ and Weissenberg number, $W e<87$. To validate the proposed model further, a residual plot has been constructed and is represented in Fig. 6. The residual values are 


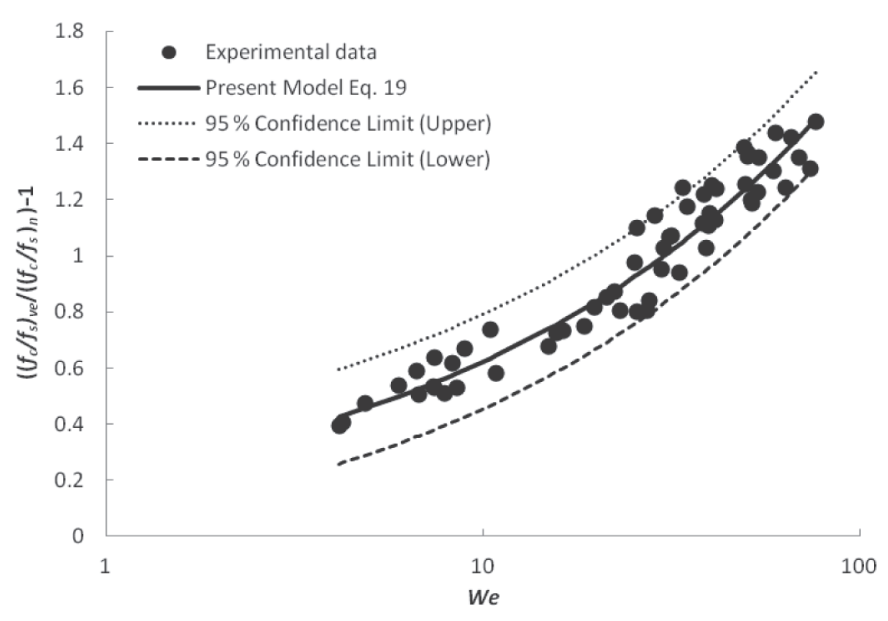

Fig. 5 - Functional relationship between $\left(\left(f_{c} / f_{s}\right)_{v e} /\left(f_{c} / f_{s}\right)_{n}\right)-1$ and We
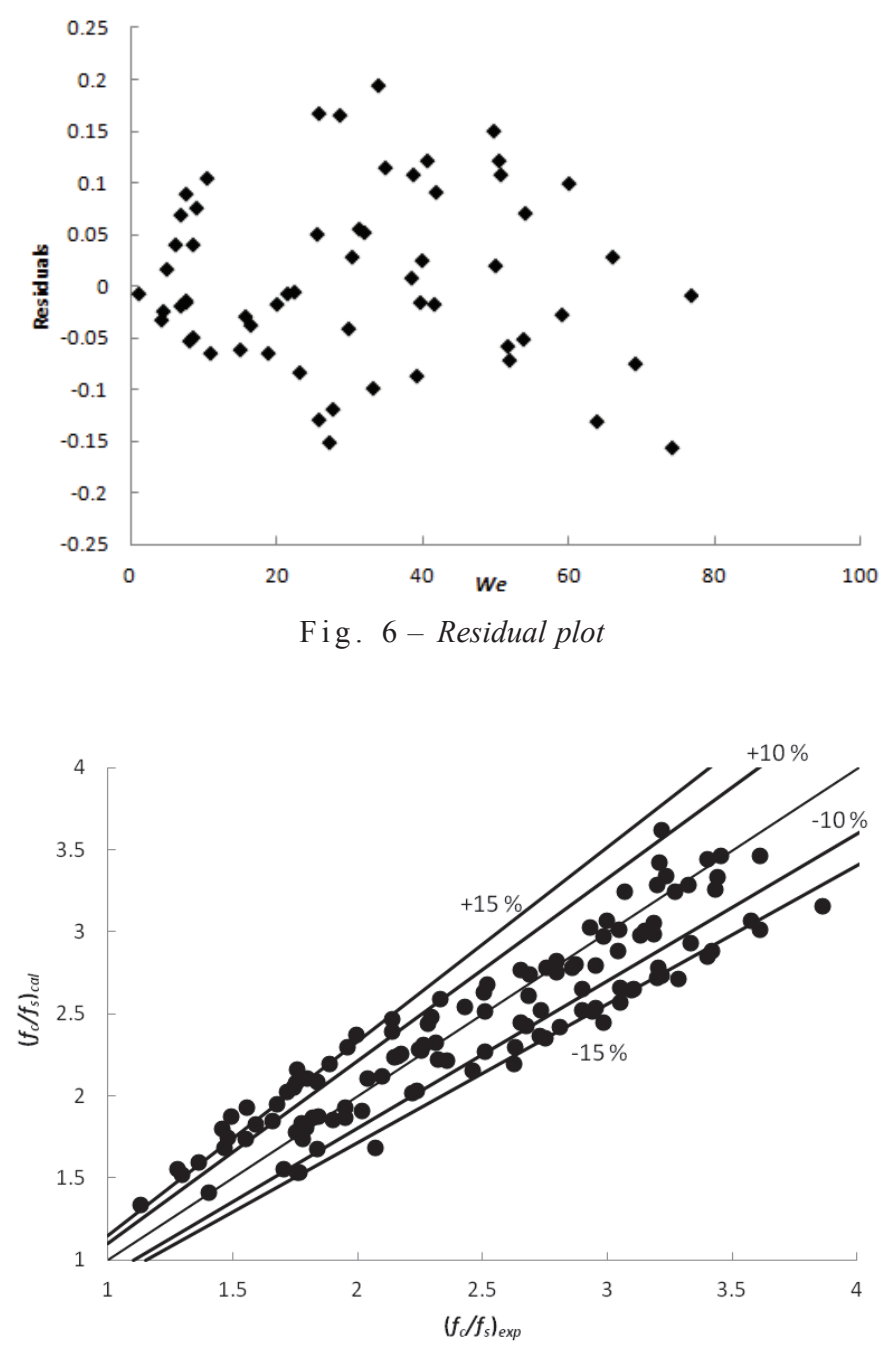

Fig. 7 - Parity between the observed friction factor ratio, $\left(\left(f_{c} / f_{s}\right)_{\text {exp }}\right)$ and the model predicted values, $\left(\left(f_{c} / f_{s}\right)_{c a l}\right)(E q .19)$ distributed randomly above and below the zero line, which depicts the acceptability of the proposed model, Eq. 19. Fig. 7 represents the parity between the observed friction factor ratio $\left(\left(f_{c} / f_{s}\right)_{\text {exp }}\right)$ and the model predicted values $\left(\left(f / f_{s}\right)_{c a l}\right)($ Eq. 19). It was observed that the model predicts the data well, to within a reasonable accuracy of $\pm 15 \%$ of the parity.

\section{Comparison with other models}

The observed pressure drop data for the flow of non-Newtonian viscoelasic fluids was compared with the models of Bandaru and Chhabra ${ }^{23}$, Mashelkar and Devaranjan ${ }^{25}$ and Pimenta and Cam$\operatorname{pos}^{26}$. The model of Mashelkar and Devaranjan ${ }^{25}$ was selected for comparison, as the authors have incorporated in their model the effect of fluid elasticity in terms of We. Further, the models of Bandaru and Chhabra ${ }^{23}$ and Pimenta and Campos ${ }^{26}$ follow the boundary condition $f_{c} \rightarrow f_{s}$ as the Dean number approaches zero and are applicable over a wide range of Dean numbers. The data were compared statistically using mean relative quadratic error $(M R Q E)$ and arithmetic relative error $(\% A R E)$ expressed in equation 20 and 21, respectively. Lower value of $M R Q E$ and $\% A R E$ implies better prediction by the model.

$$
\begin{aligned}
M R Q E & =\left(\frac{\sum\left(\frac{f_{\exp }-f_{\text {cal }}}{f_{\exp }}\right)^{2}}{N-1}\right)^{0.5} \\
\% A R E & =\frac{\sum \frac{\left|f_{\exp }-f_{c a l}\right|}{f_{\exp }}}{N} \cdot 100
\end{aligned}
$$

The obtained values of $M R Q E$ and $\% A R E$ are given in Table 4. Higher values of $M R Q E$ for the models used for comparison may be because of the following reasons:

i) The model of Bandaru and Chhabra ${ }^{23}$ was valid only for the flow of Newtonian and viscoinelastic fluids.

ii) Though the model of Mashelkar and Devaranjan $^{25}$ has incorporated the effect of fluid elasticity, the empirical correlation clearly depicts drag reduction. Further, the phenomenon of drag reduction or enhancement could be dependent on molecular weight of the polymers, which has not been speci-

Table 3 -Uncertainty analysis for the proposed model

\begin{tabular}{c|c|c|c|c|c|c|c}
\hline Average of $\left(\left(f_{c} / f_{s}\right)_{v e} /\left(f / f_{s}\right)_{n}\right)-1$ & $\mathrm{df}$ & $\mathrm{SE}$ & Critical t & CI & $\mathrm{a}$ & $\mathrm{b}$ & $R^{2}$ \\
\hline 0.9495 & 58 & 0.0842 & 2.0017 & 0.1684 & 0.23 & 0.43 & 0.99 \\
\hline
\end{tabular}


Table 4 -Statistical comparison

\begin{tabular}{|c|c|c|c|c|c|c|c|c|}
\hline \multirow{2}{*}{ Test fluid } & \multicolumn{2}{|c|}{ Present model, Eq. 19} & \multicolumn{2}{|c|}{ Bandaru and Chhabra ${ }^{23}$} & \multicolumn{2}{|c|}{$\begin{array}{l}\text { Mashelkar and } \\
\text { Devaranjan }^{25}\end{array}$} & \multicolumn{2}{|c|}{ Pimenta and campos ${ }^{2}$} \\
\hline & MRQE & \%ARE & MRQE & $\%$ ARE & MRQE & $\%$ ARE & MRQE & $\%$ ARE \\
\hline $\begin{array}{l}\text { Viscoelastic fluids } \\
\text { [PAA: } 0.25-0.5 \% \text { (wt/vol.) }]\end{array}$ & 0.0873 & 6.98 & 0.5739 & 56.33 & 0.7909 & 78.58 & 0.5984 & 58.66 \\
\hline
\end{tabular}

fied by the authors. Further, the Weissenberg number has been defined on the basis of boundary layer thickness and not the characteristic dimension of the conduit.

iii) The effect of fluid elasticity has not been effectively incorporated in the model proposed by Pimenta and Campose ${ }^{26}$.

Lower values of $M R Q E$ and $\% A R E$ for the proposed model against the models of Bandaru and Chhabra $^{23}$, Mashelkar and Devaranjan ${ }^{25}$ and Pimenta and Campos $^{26}$ suggests the acceptability of Eq. 19.

\section{Conclusions}

An extensive set of experimental data on viscoelastic fluids (aqueous solutions of polyacrylamide) flowing through helical coil have been generated. Based on the observed experimental data, it is concluded that there seems to be a critical value of Germano number $\left(N_{G n} \sim 0.002\right)$ beyond which a sharp increase in friction factor has been observed. The increased frictional resistance may be attributed to the enhanced normal stresses, which develop as a result of chain elongation, and shows the dominance of elastic effects over viscous effects. An existing correlation of Gupta et al..$^{22}$, applicable for the flow of Newtonian fluids through helical coils, has been extended for the flow of viscoelastic fluids through helical coils by incorporating the effect of fluid elasticity in terms of Weissenberg number $(W e)$. The proposed correlation predicts the data well to within a reasonable accuracy of $\pm 15 \%$ of the parity. Based on a detailed statistical analysis in terms of $M R Q E$ and $\% A R E$, it is concluded that the frictional pressure drop for the flow of Newtonian and non-Newtonian viscoelastic fluids through helical coils can safely be predicted using the proposed correlation for $N_{G n} \leq 70$, expressed as:

$$
\left(\frac{f_{c}}{f_{s}}\right)_{v e}=\left(1+0.903 N_{G n}^{0.227}\right)\left(1+0.23 W e^{0.43}\right)
$$

\section{ACKNOWLEDGMENTS}

Financial support received from the Science and Engineering Research Board (SERB), Government of India, New Delhi against letter number SR/ FTP/ETA-88/2011, TEQIP-II, and PURSE (DST), Panjab University Chandigarh is gratefully acknowledged.

\section{Abbreviations}

C - Fluid concentration, ppm

CI - Confidence interval

CMC - Carboxy methyl cellulose

$D \quad$ - Diameter of cylindrical coil support, $\mathrm{m}$

$D_{c} \quad$ - Coil diameter, m, Eq. 12b

$d_{t} \quad$ - Inside tube diameter, $\mathrm{m}$

$D_{t o} \quad$ - Outside diameter of tube, $\mathrm{m}$

df - Degrees of freedom

$f_{c} \quad-$ Friction factor for coil, Eq. 11

$f_{\text {exp }}$ - Experimental friction factor for coil, Eq. 11

$f_{c a l}-$ Calculated friction factor

$f_{s} \quad$ - Friction factor for straight tube

$g$ - Acceleration due to gravity, $\mathrm{m} \mathrm{s}^{-2}$

$G^{\prime} \quad$ - Storage modulus, $\mathrm{Pa}$

$G^{\prime \prime} \quad$ - Loss modulus, $\mathrm{Pa}$

$K \quad-$ Flow consistency index, $\mathrm{Pa} \mathrm{s}^{\mathrm{n}}$

$K^{\prime} \quad$ - Apparent flow consistency index, Pa $\mathrm{s}^{\mathrm{n}}$, Eq. 3d

$L_{c} \quad$ - Equivalent length of coil, $\mathrm{m}$, $L_{c}=N\left(D^{2}+\left(\pi\left(D_{t o}+D\right)\right)^{2}\right)^{0.5}$

$m^{\prime}$ - Apparent power law consistency coefficient, Pa s ${ }^{\mathrm{n}^{\prime}}$

$n \quad-$ Flow behavior index

$N \quad-$ Number of turns

$p \quad-$ Coil pitch, $\mathrm{m}$

PAA - Polyacrylamide

PEO - Polyethylene oxide

$R_{c} \quad$ - Radius of curvature of coil, $\mathrm{m}$

$R_{m} \quad$ - Manometer reading, $\mathrm{m}$ of $\mathrm{Hg}$

SE - Standard error

$U$ - Superficial velocity, $\mathrm{m} \mathrm{s}^{-1}$

$V \quad$ - Average velocity, $\mathrm{m} \mathrm{s}^{-1}$

XG - Xanthan gum

$\Delta P \quad$ - Pressure drop across the coil, $\mathrm{Pa}$

\section{Dimensionless numbers}

$d_{t} / D_{c}-$ Coil curvature ratio

De $\quad$ - Dean number, $D e=\operatorname{Re} \cdot\left(\frac{d_{t}}{D_{c}}\right)^{0.5}$

$D e^{\prime} \quad$ - Modified Dean number, $D e^{\prime}=\operatorname{Re} \sqrt{\frac{d_{t}}{D_{c}}}$ 
$N_{D_{m}} \quad-$ Modified Dean number, $N_{D_{m}}=\operatorname{Re} \sqrt{\frac{d_{t}}{2 R_{c}}}$

$N_{D_{2}} \quad$ - Modified Dean number based on viscosity prevailing at the mean wall shear stress, Eq. 3a

$N_{G n} \quad-$ Germano number, $N_{G n}=\operatorname{Re} \frac{\pi\left(\frac{p}{d_{t}}\right)}{\left(\frac{p}{d_{t}}\right)^{2}+\left(\frac{\pi D_{c}}{d_{t}}\right)^{2}}$

Re, $N_{R e}-$ Reynolds number, $N_{R e}=\operatorname{Re}=\frac{d_{t} \rho U}{\mu}$

$\mathrm{Re}_{2} \quad-$ Reynolds number based on viscosity prevailing at the mean wall shear stress, Eq. 3b

$\mathrm{Re} \quad-$ Modified Reynolds number, Re $=\frac{d_{t}^{n^{\prime}} \rho V^{2-n^{\prime}}}{m^{\prime} 8^{n^{n-1}}}$

$\mathrm{Re}_{\text {crit }} \quad$ - Critical Reynolds number for coil, Eq. 14

We - Weissenberg number, $W e=\frac{\lambda_{t} U}{d_{t}}$

$$
\begin{aligned}
& \text { Subscripts } \\
& \text { cal - Calculated } \\
& \exp -\text { Experimental } \\
& n \quad-\text { Newtonian fluid } \\
& v e-\text { Viscoelastic fluid }
\end{aligned}
$$

\section{Greek letters}

$\eta_{i} \quad$ - Dynamic viscosity for the $i^{\text {th }}$ element in the Maxwell model

$\dot{\gamma}-$ Wall shear rate, $\mathrm{s}^{-1}$, Eq. 13

$\lambda_{i}$ - Fluid relaxation time for the $i^{t h}$ element in the Maxwell model, s

$\lambda_{t}-$ Fluid relaxation time, $\mathrm{s}$

$\mu \quad-$ Viscosity of Newtonian fluid, Pa s

$\mu_{a}$ - Apparent viscosity for non-Newtonian fluids, Pa s

$\mu_{2}-$ Viscosity prevailing at mean wall shear stress, Pa s, Eq. 3c

$\omega \quad-$ Angular frequency, $\operatorname{rad~s}^{-1}$

$\rho_{\mathrm{Hg}}-$ Density of manometer fluid, mercury, $\mathrm{kg} \mathrm{m}^{-3}$

$\rho, \rho_{f}-$ Density of test fluid, $\mathrm{kg} \mathrm{m}^{-3}$

$\tau \quad-$ Shear stress, $\mathrm{Pa}$

$\tau_{n} \quad-$ Coil torsion, Eq. $4 \mathrm{c}$

\section{References}

1. Ali, S., Pressure drop correlations for flow through regular helical coil tubes, Fluid Dyn. Res. 28 (2001) 295. doi: https://doi.org/10.1016/S0169-5983(00)00034-4

2. Biswas, A. B., Das, S. K., Two-phase frictional pressure drop of gas-non-Newtonian liquid flow through helical coils in vertical orientation, Chem. Eng. Process 47 (2008) 816.

doi: https://doi.org/10.1016/j.cep.2007.01.030
3. Guo, L., Feng, Z., Chen, X., An experimental estimation of the frictional pressure drop of steam water two phase flow in helical coils, Int. J. Heat Mass Transfer 44 (2001) 2601. doi: https://doi.org/10.1016/S0017-9310(00)00312-4

4. Mandal, S. N., Das, S. K., Gas-liquid flow through helical coils in vertical orientation, Ind. Eng. Chem. Res. 42 (2003) 3487.

doi: https://doi.org/10.1021/ie0200656

5. Yamamoto, K., Akita, T., Ikeuchi, H., Kita, Y., Experimental study of the flow in a helical circular tube, Fluid Dyn. Res. 16 (1995) 237. doi: https://doi.org/10.1016/0169-5983(95)00022-6

6. Nigam, K. D. P., Agarwal, S., Srivastava, V. K., Laminar convection of non-Newtonian fluids in the thermal entrance region of coiled circular tubes, Chem. Eng. J. 84 (2001) 223. doi: https://doi.org/10.1016/S1385-8947(00)00376-4

7. Pawar, S. S., Sunnapwar, V. K., Experimental studies on heat transfer to Newtonian and non-Newtonian fluids in helical coils with laminar and turbulent flow, Exp. Therm. Fluid Sci. 44 (2013) 792. doi: https://doi.org/10.1016/j.expthermflusci.2012.09.024

8. Cuming, H. G., The Secondary Flow in Curved Pipes, Aeronautical Research Council Reports and Memoranda, R and M No. 2880, February 1952.

9. Barua, $S$. N., On secondary flow in stationary curved pipes, Q. J. Mech. Appl. Math. 16 (1963) Part I. doi: https://doi.org/10.1093/qjmam/16.1.61

10. Ito, $H$., Flow in curved pipes, JSME International journal 30 (1987) 543.

doi: https://doi.org/10.1299/jsme1987.30.543

11. Naphon, P., Wongwises, S., A review of flow and heat transfer characteristics in curved tubes, Renew. Sust. Energ. Rev. 10 (2006) 463. doi: https://doi.org/10.1016/j.rser.2004.09.014

12. Dean, W. R., Note on the motion of fluid in a curved pipe, Philosophical Magazine Series 74 (1927) 208. doi: https://doi.org/10.1080/14786440708564324

13. Dean, $W$. R., The stream-line motion of fluid in a curved pipe, Philosophical Magazine Series 75 (1928) 673.

14. White, C. M., Streamline flow through curved pipes, Proc. R. Soc. Lond. A 123 (1929) 645. doi: https://doi.org/10.1098/rspa.1929.0089

15. Alder, M., Strömung in Gekrümmten Rohren., Z. Angew. Math Mech. 14 (1934) 257. doi: https://doi.org/10.1002/zamm.19340140502

16. Eustice, J., Experiments on streamline motion in curved pipes, Proc. R. Soc. Lond. A (1911) 119. doi: https://doi.org/10.1098/rspa.1911.0026

17. Berger, S. A., Talbot, L., Yao, L. S., Flow in curved pipes, Ann. Rev. Fluid Mech. 15 (1983) 461. doi: https://doi.org/10.1146/annurev.fl.15.010183.002333

18. Zhou, Y., Shah, S. N., Fluid flow in coiled tubing: a literature review and experimental investigation, J. Can. Petrol. Technol. 43 (2004) 52.

doi: https://doi.org/10.2118/04-06-03

19. Vashisth, S., Kumar, V., Nigam, K. D. P., A review on the potential applications of curved geometries in process industry, Ind. Eng. Chem. Res. 47 (2008) 3291. doi: https://doi.org/10.1021/ie701760h

20. Mishra P., Gupta, S. N., Momentum transfer in curved pipes. 1. Newtonian fluids, Ind. Eng. Chem. Process Des. Dev. 18 (1979) 130. doi: https://doi.org/10.1021/i260069a017 
21. Mishra, P., Gupta, S. N., Momentum transfer in curved pipes. 2. Non-Newtonian fluids, Ind. Eng. Chem. Process Des. Dev. 18 (1979) 137. doi: https://doi.org/10.1021/i260069a018

22. Gupta, R., Wanchoo, R. K., Ali, T. R. M. J., Laminar flow in helical coils: a parametric study, Ind. Eng. Chem. Res. 50 (2011) 1150. doi: https://doi.org/10.1021/ie101752z

23. Bandaru, S. V. S. R. K., Chhabra, R. P., Pressure drop for single and two-phase flow of non-Newtonian liquids in helical coils, Can. J. Chem. Eng. 80 (2002) 315. doi: https://doi.org/10.1002/cjce.5450800219

24. Mashelkar, R. A., Devarajan, G. V., Secondary flows of non-Newtonian fluids. 1. Laminar boundary-layer flow of a generalized non-Newtonian fluid in a coiled tube, T. I. Chem. Eng-Lond. 54 (1976) 100.

25. Mashelkar, R. A., Devarajan, G. V., Secondary flow of non-Newtonian fluids. 2. Frictional losses in laminar-flow of purely viscous and viscoelastic fluids through coiled tubes, T. I. Chem. Eng-Lond. 54 (1976) 108.

26. Pimenta, T. A., Campos, J. B. L. M., Friction losses of Newtonian and non-Newtonian fluids flowing in laminar regime in a helical coil, Exp. Therm. Fluid Sci. 36 (2012) 194. doi: https://doi.org/10.1016/j.expthermflusci.2011.09.013

27. Hart, J., Ellenberger, J., Hamersma, P. J., Single and two phase flow through helically coiled tubes, Chem. Eng. Sci. 43 (1988) 775. doi: https://doi.org/10.1016/0009-2509(88)80072-1

28. McCabe, W. L., Smith, J. C., Harriott, P., Unit Operations of Chemical Engineering, $5^{\text {th }}$ edition, Chemical and Petroleum Engineering Series, McGraw Hill International Edition: Singapore, 1993, pp 83-119.
29. Srinivasan, P. S., Nandapurkar, S. S., Holland, F. A., Pressure drop and heat transfer in coils, Chem. Eng. (1968) 113.

30. Moffat, R. J., Describing the uncertainties in experimental results, Exp. Therm. Fluid Sci. 1 (1988) 3. doi: https://doi.org/10.1016/0894-1777(88)90043-X

31. Kline, S. J., McClintock, F. A., Describing uncertainties in single sample experiments, Mech. Eng. 75 (1953) 3.

32. Sobti, A., Wanchoo, R., K., Creeping flow of viscoelastic fluid through a packed bed, Ind. Eng. Chem. Res. 53 (2014) 14508 .

doi: https://doi.org/10.1021/ie502321a

33. Escudier, M. P., Evan, J. C., Poole, R. J., Freezing as a storage process for aqueous polymer solutions, Appl. Rheol. 15 (2005) 90.

34. White, J. L., Dynamics of viscoelastic fluids, melt fracture, and the rheology of fiber spinning, J. Appl. Polym. Sci. 8 (1964) 2339. doi: https://doi.org/10.1002/app.1964.070080527

35. Dealy, J. M., Weissenberg and Deborah numbers-their definition and use, Rheology Bulletin 79 (2010) 14.

36. Sobti, A., Gupta, R., Sirohi, R., Wanchoo, R. K., Pressure drop studies on flow of viscoelastic fluid through a packed bed, Particul. Sci. Technol. 31 (2013) 547. doi: https://doi.org/10.1080/02726351.2013.782934

37. Stokes, J. R., Graham, L. J. W., Borger, D. V., Observation of Elastic Effects in Confined Swirling Flow of Viscoelastic Fluids, In: Proceedings of the $12^{\text {th }}$ Australasian Fluid Mechanics Conference, University of Sydney, Australia, 1995. URL: http://people.eng.unimelb.edu.au/imarusic/ proceedings/12/Stokes.pdf (04. 10. 2015). 